Seit Jahren nimmt der Druck auf das Arztgeheimnis zu. Der gewaltsame Tod der Genfer Sozialtherapeutin Adeline M. hat in der Romandie und mittlerweile auch in der ganzen Schweiz den Druck auf das Arztgeheimnis zusätzlich erhöht. Die Regierung in Genf zielt auf das Arztgeheimnis, wohl um von verbesserungswürdigen Verwaltungsabläufen abzulenken. Die FMH unterstützt die Genfer Ärzte im Streit gegen die Aufweichung des Arztgeheimnisses.

Dr. med. Jürg Schlup, Präsident der FMH

\title{
Das Arztgeheimnis ist unantastbar
}

\section{Michel Matter}

Präsident des Ärzteverbandes des Kantons Genf AMG
Korrespondenz:

ma-matter[at]bluewin.ch
Folge des Dramas um Adelines Tod in La Pâquerette: Der Staatsrat gab am 19. März seine Absicht bekannt, für gemeingefährliche Patienten ein Gesetz zum Arztgeheimnis zu erlassen. Dieses Vorhaben ist gleich doppelt ärgerlich. Zunächst einmal gilt grundsätzlich: Das Arztgeheimnis ist unantastbar und muss es auch bleiben. Aber auch das Vorgehen bei diesem Gesetzesentwurf ist ärgerlich. Zu keinem Zeitpunkt wurde der Ärzteverband des Kantons Genf AMG konsultiert oder auch nur informiert, etwa am 17. März, als AMG-Vertreter mit Staatsrat Mauro Poggia über eine mögliche Zusammenarbeit bei diversen gesundheitspolitischen Themen sprachen. Und was soll man zum Schweigen sagen, das dem Verantwortlichen des medizinisch-psychiatrischen Dienstes für den Strafvollzug der Genfer Universitätskrankenhäuser HUG, Dr. Hans Wolff, auferlegt wurde?

Ärzteschaft und Politik verfolgen das gleiche Ziel: mehr Sicherheit zu bieten. In einem verständlicherweise sehr emotionalen Klima möchten die Politiker jetzt den Eindruck einer vollständigen Dossierfestigkeit vermitteln - umso mehr, als diese Affäre ein Versagen der eingerichteten Verfahren auf allen Ebenen zutage gefördert hat. Überall kam es zu Fehlern, aber das Arztgeheimnis hatte nichts damit zu tun. Nirgends im Bericht des ehemaligen Staatsrats Bernard Ziegler wird dem Arztgeheimnis irgendeine Rolle beim Tod Adelines zugeschrieben. Man muss sich eines klar machen: Die Wahrung des Arztgeheimnisses trägt insofern zur Sicherheit bei, als dieses die Grundlage für Vertraulichkeit und somit Vertrauen schafft. Die Schwächung des Arztgeheimnisses dagegen sorgt für Unsicherheit.

Nun will man der Bevölkerung weismachen, dass man alles im Griff habe und umfassendes Wissen ein erneutes Drama verhindern könne. Damit verkennt man, was das Arztgeheimnis ausmacht. Eine Aufhebung des Geheimnisses darf es nur in besonderen Ausnahmefällen geben. Kein Arzt wird eine Information für sich behalten, die eine andere Person in Gefahr bringen könnte. Folglich ist es untragbar, wenn Mauro Poggia sagt, die Ärztinnen und Ärzte würden sich hinter dem Arztgeheimnis verstecken (Léman Bleu, «Genève à chaud» vom 19. März 2014).
Die Verantwortung war bei uns allen eine Grundlage unseres Berufes und wichtiger Bestandteil unserer Aus- und Weiterbildung. Wir sind verantwortlich für unser medizinisches Handeln, für unsere therapeutischen Entscheidungen und für jede Wahl, die wir treffen. Voll und ganz zu seinem Handeln zu stehen ist der zentrale Aspekt unseres Berufes. Weder arbeiten wir zum Vergnügen, noch geben wir uns Illusionen hin; wir befinden uns stets in der Realität des Patienten. Daher sind diese Unterstellungen schlicht nicht der richtige Weg. Die Behörde kann nicht von sich aus in die therapeutische Beziehung eingreifen. Wenn sie dies täte, würde sie nur das System schwächen. Darüber hinaus obliegt die Handhabung der Freigänge der Straftäter nicht dem behandelnden Arzt, sondern derjenigen Fachperson, die beauftragt ist, die Behörde zu informieren.

Rechtliche Grundlage des Arztgeheimnisses ist Artikel 321 des Schweizerischen Strafgesetzbuches. Dieser ist eindeutig genug und bedarf keinerlei Ergänzungen oder Änderungen: Der Arzt kann jederzeit seinen Patienten oder die zuständige Behörde bitten, ihn von der ärztlichen Schweigepflicht zu entbinden, um zu diesem bestimmten Zeitpunkt aufgrund einer vertraulich erhaltenen Information ein ärztliches Urteil abzugeben. Dieses Urteil ist einzig für eine aktuelle Situation und nicht für alle Ewigkeit gültig. Wenn es die Situation erfordert, weiss der Arzt seine Verantwortung wahrzunehmen: Sein Ziel ist die Sicherheit, nicht der Schutz des Patienten um jeden Preis. Besonders Ärztinnen und Ärzte im Strafvollzug haben nur den Schutz Dritter im Sinn. Ich sage es noch einmal: Die Schwächung des Arztgeheimnisses erhöht die Unsicherheit. Warum also das Rad neu erfinden, warum die therapeutische Beziehung schwächen wollen?

Auch wenn das furchtbare Drama in La Pâquerette begreiflicherweise starke Emotionen hervorgerufen hat, darf das Arztgeheimnis nicht unter dem Deckmantel, dem Wunsch der Bevölkerung zu entsprechen, aufgeweicht werden. Es war der Kontrollverlust der Behörde, der zu dem Drama Adeline geführt hat, nicht das Arztgeheimnis. Und dieses muss unantastbar bleiben. 